\title{
ACTIVATION VOLUME OF FePt-TaN NANOCRYSTALLINE THIN FILMS WITH HIGH COERCIVITY
}

\author{
T. SHIMATSU, E. G. KEIM*, T. BOLHUIS and J. C. LODDER
}

Information Storage Technology Group, MESA Research Institute, ${ }^{*}$ Centre for Materials Research University of Twente, Postbus 217,7500AE, Enschede, The Netherlands

\begin{abstract}
Coercivity and magnetic aftereffect of nanocrystalline $\mathrm{Ll}_{0}$ type FePt films is discussed in connection with magnetocrystalline anisotropy and grain size. Magnetocrystalline anisotropy field shows very large value up to more than $40 \mathrm{kOe}$ dependent on annealing temperature. This large magnetocrystalline anisotropy enabled to maintain large $\mathrm{K}_{\mathrm{u}} \mathrm{V} / \mathrm{kT}$ value more than 40 (10 years stability) even with very fine grain size of $7-8 \mathrm{~nm}$, which described the potential of this alloy film to resist thermal fluctuation of magnetisation. Although intergranular exchange coupling enhances the thermal stability of the films, it is successfully described that the change in magnetic viscosity is qualitatively coincident with that of $\mathrm{K}_{\mathrm{u}} \mathrm{V} / \mathrm{kT}$ value. Activation volume $V_{a c}$ of these films is much larger than grain volume, which is likely to be attributable to the existence of intergranular exchange coupling.
\end{abstract}

Key words: FePt nanocrystalline films, magnetocrystalline anisotropy, coercivity, magnetic aftereffect, activation volume

\section{INTRODUCTION}

The reduction of grain size is essentially required for thin film recording media to achieve ultrahigh density recording [1]. However, the size reduction degrades magnetic viscosity owing to thermal agitation of magnetic moment [2]. Therefore experimental analysis of magnetic viscosity phenomena is now very important to understand magnetisation reversal and coercive force mechanism of thin magnetic films. In the present study, we fabricated nanocrystalline FePt films, and discuss coercivity and magnetic aftereffect of the films in connection with magnetocrystalline anisotropy and grain size.

\section{EXPERIMENTAL PROCEDURE}

Nanocrystalline FePt thin films were fabricated by a thermal crystallization. from amorphous structure. $\left(\mathrm{Fe}_{50} \mathrm{Pt}_{50}\right)_{80} \mathrm{Ta}_{20} \mathrm{~N}$ films were fabricated by conventional r.f. sputtering with $\mathrm{Ar}+\mathrm{N}_{2}$ plasma under an $\mathrm{N}_{2}$ gas flow ratio $\mathrm{F}=\mathrm{N}_{2} /\left(\mathrm{Ar}+\mathrm{N}_{2}\right)$ of $30 \%$. Total gas pressure was fixed at $30 \mathrm{mTorr}$. Films were deposited on non-textured quartz substrates, and film thickness was fixed at $10 \mathrm{~nm}$. Films were crystallized by an annealing process in vacuum $\left(10^{-6}\right.$ mbar) at various temperatures from 600 to $670{ }^{\circ} \mathrm{C}$ for about $30 \mathrm{~min}$. In each measurement of the time dependence of magnetization, the sample was initially saturated with a positive field of $30 \mathrm{kOe}$, and then a constant negative testing field was applied. Coercivity was measured at various sweeping rates of $12.5 \sim 200 \mathrm{Oe} / \mathrm{sec}$.

\section{RESULT AND DISCUSSION}

Fig.1 shows TEM bright field images of the samples respectively annealed at 600 and $650^{\circ} \mathrm{C}$. It is clearly seen that fabricated films successfully consist of nanocrystalline grains less than $10 \mathrm{~nm}$. TEM diffraction patterns revealed that these grains are fct-FePt ( $\mathrm{LI}_{0}$ tetragonal phase), and (101) crystallographic plane are almost parallel to the film plane. Although the formation of TaN was expected at the grain boundary of FePt because of strong bond between $\mathrm{Ta}$ and nitrogen, clear diffraction coming from $\mathrm{TaN}$ phase were not observed in the diffraction patterns. With increasing annealing temperature, $T_{A}$, the mean grain size of FePt was found to increase almost linearly from about 5 $\mathrm{nm}\left(\mathrm{T}_{\mathrm{A}}=600^{\circ} \mathrm{C}\right)$ to about $8 \mathrm{~nm}\left(650^{\circ} \mathrm{C}\right)$.

Fig. 2 shows a $T_{A}$ dependence of coercivity $H_{C}$. The films show isotropic magnetic property in the film plane. The given $\mathrm{H}_{c}$ values are those measured at $50 \mathrm{Oe} / \mathrm{sec}$ in sweeping rate, $\mathrm{dH} / \mathrm{dt}$. The value of $\mathrm{H}_{c}$ increases with increasing $\mathrm{T}_{\mathrm{A}}$, and goes beyond $3 \mathrm{kOe}$ at $650{ }^{\circ} \mathrm{C}$. This temperature is about $150^{\circ} \mathrm{C}$ higher than that of pure $\mathrm{FePt}$ alloy films prepared in $\mathrm{Ar}+4 \% \mathrm{H}_{2}$ atmosphere [3]. Saturation magnetisation $\mathrm{M}_{\mathrm{S}}$ shows almost a constant value of about $550 \mathrm{emu} / \mathrm{cm}^{3}$ at higher $T_{A}$ than $620^{\circ} \mathrm{C}$. It should be noted here that the squareness of magnetization curve, $\mathrm{M}_{\mathrm{p}} / \mathrm{M}_{s}$, kept almost a constant value of about 0.75 against $T_{A}$, even though the $H_{c}$ drastically increases.

Magnetocrystalline anisotropy field, $\mathrm{H}_{\mathrm{k}}{ }^{\mathrm{grain}}$, was estimated by a measurement of rotational hysteresis loss, $W_{r}$, as a function of applied field, $H$. The value of $\mathrm{H}_{\mathrm{k}}$ grain was defined as a field where $W_{r}$ vanishes by using extrapolation method in the $\mathrm{W}_{\mathrm{r}} \sim 1 / \mathrm{H}$ plot [4].
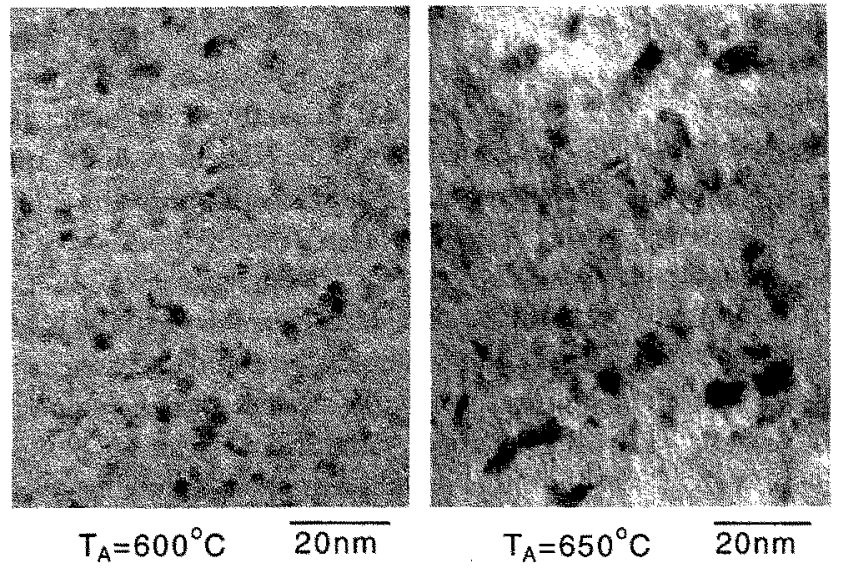

Fig.I TEM bright field images of the samples. 


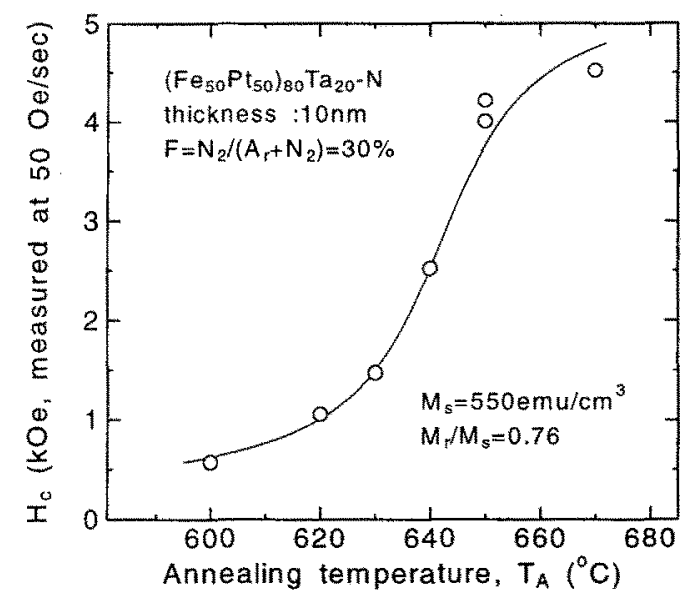

Fig.2 Annealing temperature $T_{A}$ dependence of $H_{C}$.

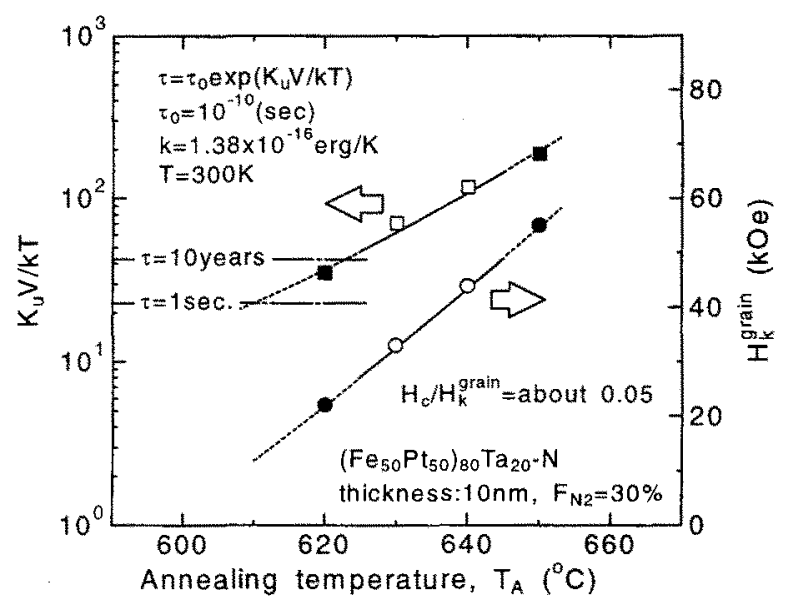

Fig.3 The values of magnetocrystalline anisotropy field Hkgrain and calculated $K_{u} V / k T$ as a function of $T_{A}$. Close marks mean that these values were obtained under an assumption that the $H_{k}^{\text {grain }}$ value linearly increases within this $T_{A}$ range.

Fig. 3 shows the values of $\mathrm{H}_{k}^{\text {grain }}$ and calculated $\mathrm{K}_{\mathrm{u}} \mathrm{V} / \mathrm{kT}$ as a function of $T_{A}$. Here, $K_{u}=H_{k}{ }^{\text {grain }} M_{s} / 2, V$ is the volume of a grain, $k$ is the Boltzmann constant, and $T$ is temperature $(\mathrm{K})$. The values of $\mathrm{K}_{\mathrm{u}} \mathrm{V} / \mathrm{kT}$ which give thermal relaxation time $\tau=1$ second and 10 years by using Arrhenius Neel law are respectively shown in the figure. The value of $\mathrm{H}_{k}{ }^{\text {grain }}$ at 630 and $640^{\circ} \mathrm{C}$ showed large values respectively of about 33 and $44 \mathrm{kOe}$. These values are several times larger than those of Co based thin film media [4]. The series of the $W_{t} \sim 1 / H$ curves from $T_{A}=600$ to 650 ${ }^{\circ} \mathrm{C}$ indicated that $\mathrm{H}_{\mathrm{k}}{ }^{\text {grain }}$ drastically increases with increasing $T_{A}$ within this region. However the $\mathrm{H}_{k}{ }^{\text {grain }}$ values at 600 and $620^{\circ} \mathrm{C}$ were impossible to be estimated because of unstable magnetic torque in these films, which may be attributable to magnetic aftereffect during the measurement. On the other hand, the $\mathrm{H}_{\mathrm{k}}^{\text {grain }}$ values at 650 ${ }^{\circ} \mathrm{C}$ was not possible to be estimated either, because the maximum applied field of the measurement system was not enough to determine $\mathrm{H}_{\mathrm{k}}^{\text {grain }}$ value by the extrapolation method in the $\mathrm{W}_{\mathrm{r}} \sim 1 / \mathrm{H}$ plot. Because of these reasons, the $\mathrm{H}_{\mathrm{k}}$ grain values given at 620 and $650^{\circ} \mathrm{C}$ in the figure were estimated by using those at 630 and $640{ }^{\circ} \mathrm{C}$ under an assumption that the $\mathrm{H}_{\mathrm{k}}{ }^{\text {grain }}$ value linearly increases within this $T_{A}$ range. The calculated $K_{u} V / k T$ value is found to increase drastically with increasing $T_{A}$ due to the increases of $\mathrm{V}$ and $\mathrm{K}_{\mathrm{u}}$. It should be noted here that induced large magnetocrystalline anisotropy enables to maintain large $\mathrm{K}_{\mathrm{u}} \mathrm{V} / \mathrm{kT}$ value more than 40 (10 years stability) even with very fine grain size of $7 \sim 8 \mathrm{~nm}$ (in the $T_{A}$ region more 630 ${ }^{\circ} \mathrm{C}$ ), which obviously indicates the high potential of $\mathrm{Ll}_{0}$ type FePt to resist thermal fluctuation.

On the other hand, the values of normalised coercive force $\mathrm{H}_{\mathrm{c}} / \mathrm{H}_{\mathrm{k}}$ grain generally indicates the strength of intergranular exchange coupling [4,5]. The $\mathrm{H}_{c} / \mathrm{H}_{\mathrm{k}}$ grain value of the present samples is almost a constant of 0.05 0.07. This suggests that the degree of intergranular magnetic coupling does not change remarkably against $\mathrm{T}_{\mathrm{A}}$. It should be mentioned here that these values of $\mathrm{H}_{\mathrm{c}} / \mathrm{H}_{\mathrm{k}}{ }_{\mathrm{k}}^{\text {gratin }}$ are a few times smaller than that of Co based thin film media [4], and several times smaller than the simulated value for the ideal media with no intergranular exchange coupling $\left(\mathrm{H}_{c} / \mathrm{H}_{\mathrm{k}}^{\text {grain }}=\right.$ about 0.45 ) $[2,5]$. This result means that there is still a certain strength of intergranular exchange coupling.

In the measurement of time dependence of magnetization, almost logarithmic time decay have been observed under constant negative applied fields for all samples, and we show the representative behaviour in fig.4. Viscosity coefficient S [6] is determined as an slope of the $M(t) \sim \ln t$ as follows.

$$
M(t)=M_{0}-S \ln t
$$

Here, $M_{0}$ is a constant magnetization. The values of $M_{0}$ and $S$ are clearly dependent on applied field $\mathrm{H}_{\mathrm{a}}$.

Fig.5 shows $\mathrm{S}$ values as a function of $\mathrm{H}_{\mathrm{a}}$. The $\mathrm{S}$ value at $\mathrm{H}_{2}=0$ was very small less than a few $\mathrm{erg} / \mathrm{cm}^{3}$ in every sample. Although the trend of $K_{u} V / k T \sim T_{A}$ plot in the fig. 3 suggests that the $\tau$ value at $600{ }^{\circ} \mathrm{C}$ is much smaller than the measurement time scale, this sample is also thermally stable when $\mathrm{H}_{\mathrm{a}}=0$. This is attributable to the existence of intergranular exchange coupling [7]. On the other hand, the $S$ value is found to show the maximum at around $H_{a}=-H_{c}$ in all the samples. Particularly the $S$ of the $T_{A}=600^{\circ} \mathrm{C}$ sample shows a very large value of about $48 \mathrm{emu} / \mathrm{cm}^{3}$ which corresponds to about $23 \%$ decay of $S / M_{\mathrm{r}}$ value by the increment of observation time a factor of 10 . The $S$ value at $H_{a}=-H_{c}$ remarkably decreases with increasing $T_{A}$, which is well coincident with the change in $\mathrm{K}_{\mathrm{u}} \mathrm{V} / \mathrm{kT}$ value in fig. 3 .

Street and Woolley proposed [6] the following relationship between $S$ and the irreversible susceptibility $\chi_{i r r}$, which defines fluctuation field $\mathrm{H}_{f}$,

$$
\mathrm{S}=\chi_{\mathrm{irr}} \mathrm{H}_{\mathrm{f}}
$$




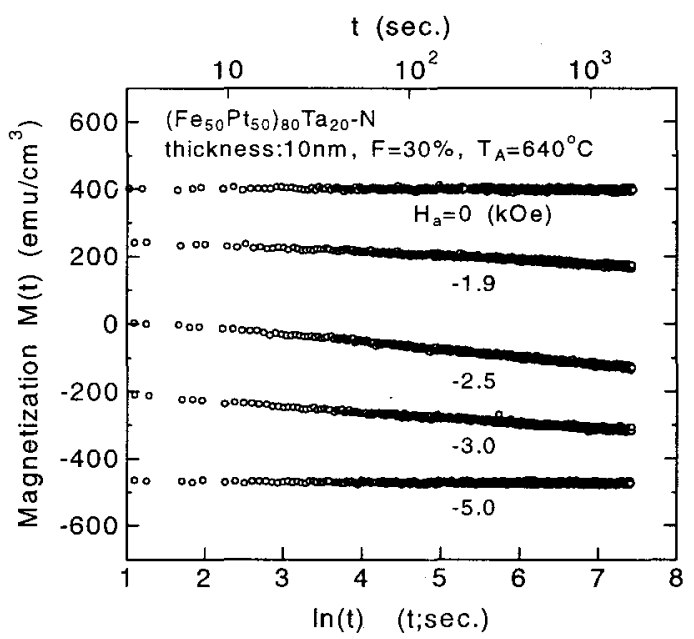

Fig.4 Time dependence of magnetization $M(t)$ at various applied field $H_{a}$.

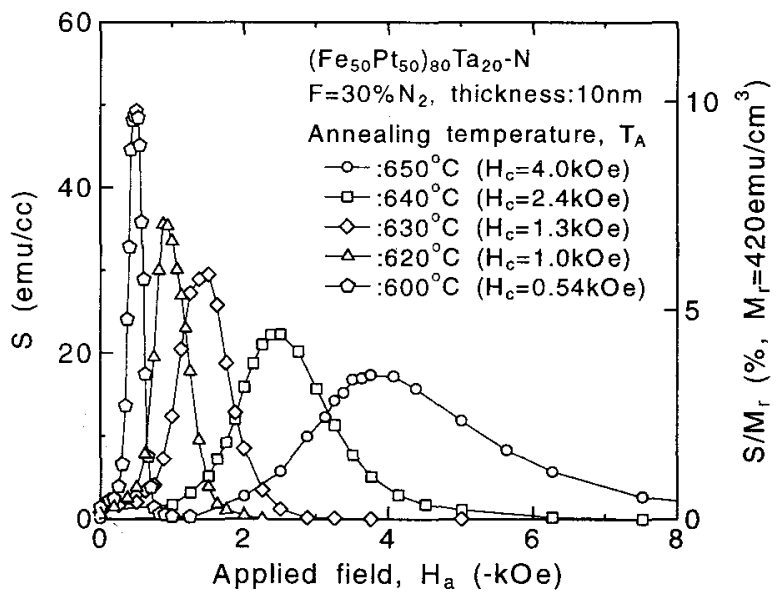

Fig.5 Applied field dependence of viscosity coefficient $S$.

Fig.6 shows a representative $\mathrm{H}_{\mathrm{a}}$ dependence of $\mathrm{H}_{\mathrm{f}}$ determined by using eq.(2). Here, $\chi_{\text {irr }}$ is the differential of the remanent magnetisation curve. The $\mathrm{H}_{\mathrm{a}}$ dependences of $S$ and $\chi_{\text {irr }}$ are shown in the inserted figure. With increasing $\mathrm{H}_{\mathrm{a}}$, the value of $\mathrm{H}_{\mathrm{f}}$ drastically drops, and shows almost a constant in the range of field values larger than $\mathrm{H}_{\mathrm{c}}$ for which it can accurately be measured. Here, the dotted line in the figure corresponds to $\mathrm{H}_{\mathrm{a}}$ dependence of $\mathrm{H}_{\mathrm{f}}$ values theoretically calculated for a uniaxial non-interacting fine particles system with randomly oriented anisotropy axes [8], with using $\mathrm{H}_{\mathrm{k}}{ }^{\text {grain }}$ value experimentally obtained. The value of $\mathrm{H}_{\mathrm{f}}$ in the range of field values larger than $\mathrm{H}_{\mathrm{c}}$ is found to be much smaller than that theoretically obtained, and this may be attributable to the enhancement of thermal stability due to the intergranular exchange coupling in these films. On the contrary, in the range of field values close to zero, $S$ shows certain values even though $\chi_{\text {irr }}$ is almost zero, resulting in the large $\mathrm{H}_{\mathrm{f}}$ values. It should be noted here that $\mathrm{H}_{\mathrm{f}}$ in this field range is larger than that of non-interacting system. It is assumed in this field range that local

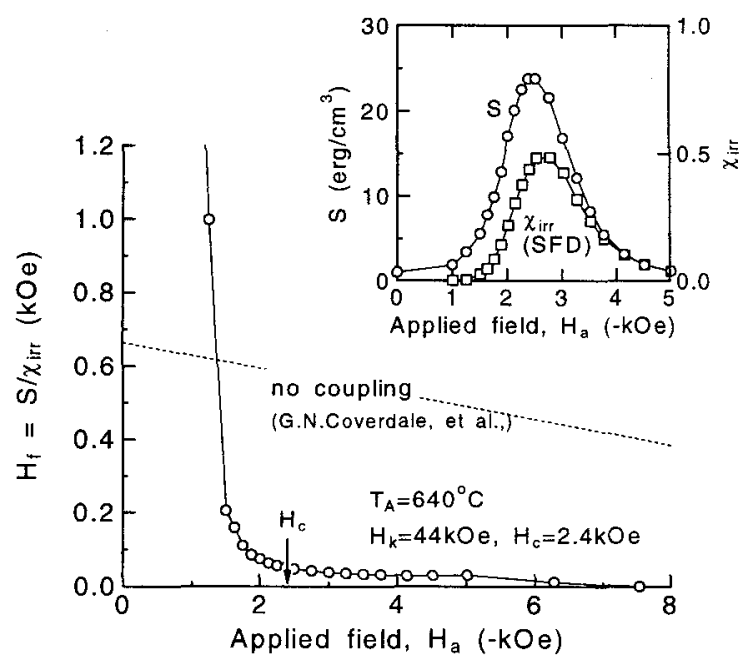

Fig.6 Applied field dependences of $H_{f}, \chi_{i r r}$ and $S$ of the sample with $T_{A}=640^{\circ} \mathrm{C}$.

magnetizations still remain almost parallel to each other in the direction of plus field initially saturated. It is likely that the large values of $\mathrm{H}_{\mathrm{f}}$ in this field range are associated with strong intergranular exchange interaction which promotes the magnetized state.

Another representative magnetic aftereffect is the frequency dependence of the coercivity and this has been studied mainly in particulate media [9-11]. A following expression [9-11] based on coherent rotation has been successfully used to represent this phenomena.

$$
H_{c}\left(t^{\prime}\right)=H_{k}\left\{1-\left(\left(k T / K_{u} V\right) \ln \left(A t^{\prime}\right)\right)^{n}\right\}
$$

where $\mathrm{A}$ is a numerical factor, $\mathrm{n}$ is the value from 0.5 to 1 dependent on anisotropy axes orientation and/or based assumption for calculation [10,12], and $t^{\prime}$ is the time needed for a constant field equal to $\mathrm{H}_{c}$ to reduce the magnetisation from saturation remanence to zero. Intuitively, it is expected that this 't' will have an approximately inverse relationship with the sweep rate of applied field $\mathrm{dH} / \mathrm{dt}$.

Fig. 7 shows the values of $\Delta \mathrm{H}_{c} / \mathrm{H}_{\mathrm{co}}$ as a function of logarithmic scale of $\mathrm{dH} / \mathrm{dt}$. Here, $\mathrm{H}_{\mathrm{co}}$ is coercivity at $\mathrm{dH} / \mathrm{dt}$ $=1 \mathrm{Oe} / \mathrm{second}$, and $\Delta \mathrm{H}_{\mathrm{c}}$ is the difference of coercivity at certain $\mathrm{dH} / \mathrm{dt}$ value and $\mathrm{H}_{\mathrm{c} 0}$. The value of $\Delta \mathrm{H}_{\mathrm{c}} / \mathrm{H}_{\mathrm{c} 0}$ is found to increase linearly with increasing $\ln (\mathrm{dH} / \mathrm{dt})$ in the present observation range of $\ln (\mathrm{dH} / \mathrm{dt})$ values. It is obvious that the slope in the $\Delta \mathrm{H}_{\mathrm{c}} / \mathrm{H}_{\mathrm{c} 0^{\sim}} \ln (\mathrm{dH} / \mathrm{dt})$ plot decreases with increasing $T_{A}$, which is well coincident with the change in $\mathrm{K}_{\mathrm{u}} \mathrm{V} / \mathrm{kT}$ mentioned above.

These magnetic aftereffect experimentally observed enables an estimation of activation volume $V_{\text {act }}$ of these films. Wohlfarth [13] proposed the following relationship between $\mathrm{H}_{\mathrm{f}}$ and $\mathrm{V}_{\mathrm{act}}$,

$$
\mathrm{V}_{\mathrm{act}}=\mathrm{kT} /\left(\mathrm{H}_{\mathrm{f}} \mathrm{M}_{\mathrm{s}}\right)
$$




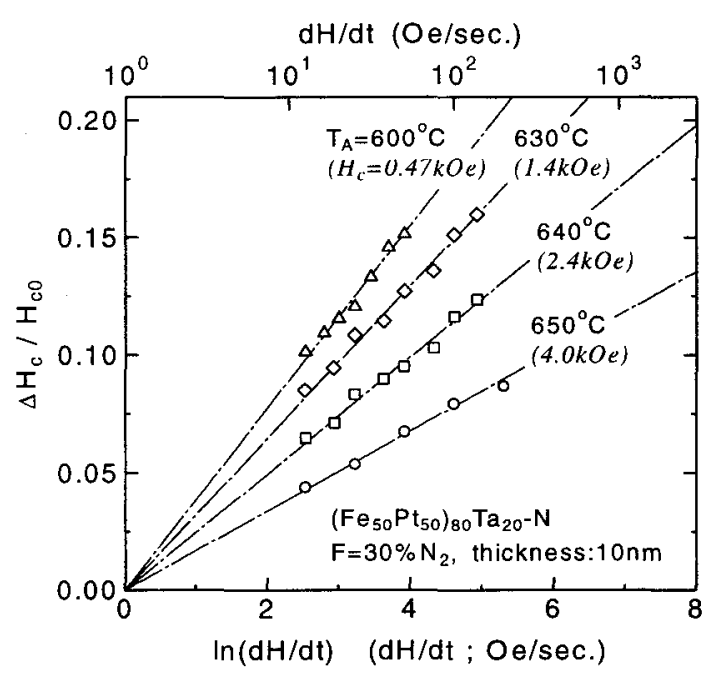

Fig. 7 The values of $\Delta H_{c} / H_{c 0}$ as a function of logarithmic scale of $\mathrm{dH} / \mathrm{dt}$.

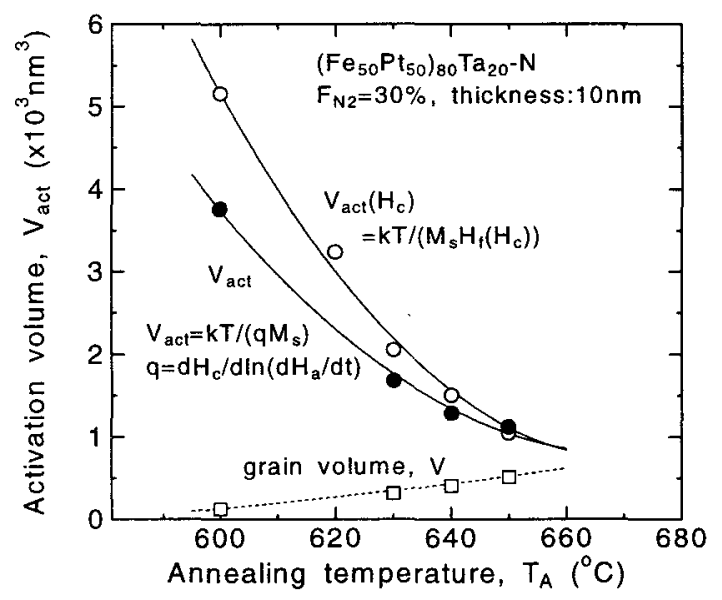

Fig.8 $T_{A}$ dependence of activation volume $V_{\text {act }}$ with that of grain volume $V$.

The value of $V_{a c t}$ is obviously field dependent. On the other hand, Bruno et al. proposed [12] the following relationship between $V_{\text {act }}$ and the sweeping rate dependent coercivity.

where

$$
\mathrm{V}_{\mathrm{act}}=\mathrm{kT} /(\mathrm{qMs}),
$$

$$
\mathrm{q}=\mathrm{dH}_{\mathrm{c}} / \mathrm{d}(\ln (\mathrm{dH} / \mathrm{dt}))
$$

Fig. 8 shows the values of $\mathrm{V}_{\mathrm{act}}$ at $\mathrm{H}_{\mathrm{a}}=-\mathrm{H}_{\mathrm{c}}$, calculated by using eq.(4), as a function of $\mathrm{T}_{\mathrm{A}}$. In the figure, the values of $\mathrm{V}_{\text {act }}$ obtained by using eq.(5), and grain volume $\mathrm{V}$ are also shown in comparison. The values of $\mathrm{V}_{\text {act }}$ obtained by using eqs.(4) and (5) are quantitatively well agreed with each other. The value of $V_{a c t}$ drastically decreases with increasing $T_{A}$. It should be noted here that $V_{\text {act }}$ values are much larger than $V$ values particularly at lower $T_{A}$, which is completely different from the behaviours observed in particulate films or systems [14]. This characteristic property is assumed to be caused by the intergranular exchange coupling although the difference between $V_{\text {act }}$ and $\mathrm{V}$ is much more enhanced than that theoretically computed [15].

\section{SUMMARY}

We experimentally described the potential of $\mathrm{L}_{0}$ type FePt alloy to resist thermal fluctuation of magnetisation. Magnetocrystalline anisotropy field shows very large value up to more than $40 \mathrm{kOe}$ dependent on annealing temperature. This large magnetocrystalline anisotropy enabled to maintain large $\mathrm{K}_{\mathrm{u}} \mathrm{V} / \mathrm{kT}$ value more than 40 (10 years stability) even with very fine grain size of 7 8 $\mathrm{nm}$. Although intergranular exchange coupling enhances the stability of the films to resist thermal fluctuation, it is successfully described that the change in magnetic viscosity is qualitatively coincident with that of $K_{u} V / k T$ value. Activation volume $\mathrm{V}_{\mathrm{act}}$ of these films is much larger than grain volume, which is likely to be attributable to the existence of intergranular exchange coupling.

\section{REFERENCES}

[1] D. N. Lambeth, E. M. T. Velu, G. H. Bellesis, L. L. Lee, and D. E. Laughlin, J. Appl. Phys., vol. 79, pp. 44964501, April 1996.

[2] S. H. Charap, Pu-Ling Lu, and Yanjun He, IEEE Trans. Magn., vol. 33, pp. 978-983, January 1997.

[3] K. R. Coffey, M. A. Parker and J. K. Howard, IEEE Trans. Magn., vol. 31, pp. 2737-2739, November 1995.

[4] T. Shimatsu, M. Takahashi, M. Suekane, M. Miyamura, K. Yamaguchi and H. Yamasaki, Trans. Mat. Res. Soc. Jpn., vol. 15B, pp. 777-782, 1994.

[5] J-G. Zhu and H. N. Bertram, J. Appl. Phys., vol. 63, pp. 3248-3253, April 1988.

[6] R. Street and J. C. Woolley, Proc. Phys. Soc. A62, pp. 562-572, 1949.

[7] Pu-Ling Lu and Stanley. H. Charap, IEEE Trans. Magn., vol. 30, pp. 4230-4232, November 1994.

[8] G. N. Coverdale, R. W. Chantrell and K. O'Grady, J. Magn. Mang. Mater., vol. 83, pp. 442-444, 1990.

[9] M. P. Sharrock, IEEE Trans. Magn., vol. 26, pp. 193197 January 1990.

[10] M. P. Sharrock, J. Appl. Phys., vol. 76, pp. 64136418, November 1994.

[11] P. J. Flanders and M. P. Sharrock, J. Appl. Phys., vol. 62, pp. 2918-2928, October 1987.

[12] P. Bruno, G. Bayreuther, P. Beauvillain, C. Chappert, G. Lugert, D. Renard, J. P. Renard, and J. Seiden, J. Appl. Phys. Vol. 68, pp. 5759-5766, December 1990.

[13] E. P. Wohlfarth, J. Phys. F: Met. Phys., vol. 14, pp. L155-L159, 1984.

[14] R. W. Chantrell, J. Magn. Magn. Mater., vol. 95, pp. 365-378 (1991).

[15] R. W. Chantrell, A. Lyberatos and E. P. Wohlfarth, J. Phys. F: Met. Phys., vol. 16, pp. L145-L150, 1986. 